\title{
Temperature and humidity sensitive ceramic materials in thick-film performance for multifunctional sensor application
}

\author{
Klym Halyna ${ }^{1,2}$, Hadzaman Ivan ${ }^{1}$, Shpotyuk Oleh ${ }^{1,3}$, Brunner Michael $^{4}$ \\ ${ }^{1}$ Lviv Scientific Research Institute of Materials of SRC "Carat", \\ 202, Stryjska str., 79031, Lviv, Ukraine \\ ${ }^{2}$ Lviv Polytechnic National University, 12, Bandera str., 79013, Lviv, Ukraine \\ ${ }^{3}$ Institute of Physics of Jan Dlugosz University, \\ 13/15, Al. Armii Krajowej, 42201 Czestochowa, Poland \\ ${ }^{4}$ Fachhochschule Köln / University of Applied Sciences, \\ 2, Betzdorfer Strasse, 50679, Köln, Germany \\ Phone: 80322638303, e-mail: klymha@yahoo.com
}

\begin{abstract}
Temperature and humidity sensitive thick-film materials based on spinel-type $\mathrm{NiMn}_{2} \mathrm{O}_{4}-\mathrm{CuMn}_{2} \mathrm{O}_{4}-$ $\mathrm{MnCo}_{2} \mathrm{O}_{4}$ manganites with $\mathrm{p}$ - and $\mathrm{p}^{+}$-types of electrical conductivity and dielectric magnesium aluminate $\mathrm{MgAl}_{2} \mathrm{O}_{4}$ were prepared. These elements are shown to be successfully applied for integrated temperature/humidity sensors of environment monitoring and control.
\end{abstract}

Keywords: spinel, thick-film, sensor, multilayer structure

\section{Introduction}

Spinel-type ceramics based on mixed transition-metal manganites and/or magnesium aluminates are known to be widely used for temperature measurement, in-rush current limiting, liquid and gas sensing, flow rate monitoring and indication, etc. [1-5]. But their sensing functionality is sufficiently restricted because of bulk performance allowing, as a rule, no more than one kind of application. The aim of this work is to develop the high-reliable multifunctional sensors based on the above spinel-type compounds, allowing integrated temperature-humidity sensitivity for effective environment monitoring and control.

At the present time, a number of important problems connected with hybrid microelectronic circuits, multilayer ceramic circuits, temperature sensors, thermal stabilizers, etc. requires such resolution, when not bulk (e.g. sintered as typical bulk ceramics), but only thick-film performance of electrical components (possessing the possibility to group-technology route) is needed [5]. The well-known advantages of screen printing technology revealed in high reproducibility, flexibility, attainment of high reliability by glass coating as well as excellent accuracy, yield and interchangeability by functional trimming are expected to be very attractive now, for new-generation sensing electronics [6]. No less important is the factor of miniaturization for developed thick-film elements and systems, realized in a variety of their possible geometrical configurations. Thus, the development of high-reliable nanostructured thick films and their multilayers based on spinel-type compounds for multifunctional environment sensors operating as simultaneous negative temperature coefficient thermistors and integrated temperature-humidity sensors are very important task [6-8].

To fabricate the integrated temperature-humidity thick-film sensors, only two principal approaches have been utilized, they being grounded on temperature dependence of electrical resistance for humiditysensitive thick films and/or on humidity dependence of electrical resistance for temperature-sensitive thick films.

The first approach was typically applied to perovsite-type thick films like to $\mathrm{BaTiO}_{3}$ [9]. Within second approach grounded on spinel-type ceramics of mixed $\mathrm{Mn}-\mathrm{Co}-\mathrm{Ni}$ system with $\mathrm{RuO}_{2}$ additives, it was shown that temperature-sensitive elements in thick-film performance attain additionally good humidity sensitivity [10]. Despite improved long-term stability and temperature-sensitive properties with character material B constant value at the level of $3000 \mathrm{~K}$, such thick-film elements possess only small humidity sensitivity. This disadvantage occurred because of relatively poor intrinsic pore topology proper to semiconducting mixed transition-metal manganited in contrast to dielectric aluminates with the same spinel-type structure.

Thick-film performance of mixed spinel-type manganites restricted by $\mathrm{NiMn}_{2} \mathrm{O}_{4}-\mathrm{CuMn}_{2} \mathrm{O}_{4}-\mathrm{MnCo}_{2} \mathrm{O}_{4}$ concentration triangle has a number of essential advantages, non-available for other ceramic composites. Within the above system, can be prepare the fine-grained semiconductor materials possessing $p^{+}$-type $\left(\mathrm{Cu}_{0.1} \mathrm{Ni}_{0.1} \mathrm{Co}_{1.6} \mathrm{Mn}_{1.2} \mathrm{O}_{4}\right)$ and $\mathrm{p}$-type of electrical conductivity $\left(\mathrm{Cu}_{0.1} \mathrm{Ni}_{0.8} \mathrm{Co}_{0.2} \mathrm{Mn}_{1.9} \mathrm{O}_{4}\right)$. So, a real possibility 
to prepare multilayer thick-film spinel-type structures for principally new device application, such as temperature-sensitive $p+-p$ junctions seems to be a quite realistic one. In addition, the prepared multilayer thick-film structures involving semiconductor $\mathrm{NiMn}_{2} \mathrm{O}_{4}-\mathrm{CuMn} \mathrm{O}_{4}-\mathrm{MnCo}_{2} \mathrm{O}_{4}$ and dielectric $\mathrm{MgAl}_{2} \mathrm{O}_{4}$ spinels can be used as simultaneous thermistors and integrated temperature-humidity sensors with extremely rich range of exploitation properties.

The aim of this work is development and selection the high-reliable separate temperature and humidity sensitive thick-film elements based on spinel-type ceramics for multifunctional application in integrated temperature/humidity sensors.

\section{Experimental}

Bulk temperature sensitive ceramics were prepared by a conventional ceramics processing route using reagent grade cooper carbonate hydroxide and nickel (cobalt) carbonate hydroxide hydrates [11]. Chemical composition of these ceramics and the main points in their sintering schedules are presented in Table 1.

Table 1

Characteristics of temperature sensitive bulk ceramics

\begin{tabular}{|c|c|c|c|}
\hline $\begin{array}{c}\text { Chemical } \\
\text { composition }\end{array}$ & $\begin{array}{c}\text { Sintering } \\
\text { temperature/duration }\end{array}$ & $\begin{array}{c}\text { Phase } \\
\text { composition }\end{array}$ & $\begin{array}{c}\mathrm{B}_{25 / 85,} \\
\mathrm{~K}\end{array}$ \\
\hline $\mathrm{Cu}_{0,1} \mathrm{Ni}_{0,1} \mathrm{Co}_{1,6} \mathrm{Mn}_{1,2} \mathrm{O}_{4}$ & $1040{ }^{\circ} \mathrm{C} / 4 \mathrm{~h}$ & spinel & 3540 \\
\hline $\mathrm{Cu}_{0,1} \mathrm{Ni}_{0,8} \mathrm{Co}_{0,2} \mathrm{Mn}_{1,9} \mathrm{O}_{4}$ & $920^{\circ} \mathrm{C} / 8 \mathrm{~h}+1200^{\circ} \mathrm{C} / 1 \mathrm{~h}$ & spinel $+\mathrm{NiO}(11.5 \%)$ & 3378 \\
& $+920^{\circ} \mathrm{C} / 24 \mathrm{~h}$ & \\
\hline
\end{tabular}

The bulk $\mathrm{MgAl}_{2} \mathrm{O}_{4}$ ceramics were prepared via conventional sintering route as was described in more details elsewhere $[12,13]$. The pellets were sintered in a special regime with maximal temperature $T_{s}$ $1300{ }^{\circ} \mathrm{C}$ during $5 \mathrm{~h}$. In a result, the humidity-sensitive ceramics with a so-called trimodal pore size distribution and character values of pore radiuses centered near $\sim 2.5,85$ and $450 \mathrm{~nm}$ and surface area near $6.93 \mathrm{~m}^{3} / \mathrm{g}$ were obtained.

Temperature sensitive $\mathrm{Cu}_{0,1} \mathrm{Ni}_{0,1} \mathrm{Co}_{1,6} \mathrm{Mn}_{1,2} \mathrm{O}_{4} / \mathrm{Cu}_{0,1} \mathrm{Ni}_{0,8} \mathrm{Co}_{0,2} \mathrm{Mn}_{1,9} \mathrm{O}_{4}$-based and humidity sensitive $\mathrm{MgAl}_{2} \mathrm{O}_{4}$-based pastes were prepared by mixing powders of basic ceramics (sintered bulk ceramics were preliminary destroyed, wet-milled and dried) with ecological glass powders (without PbO), inorganic binder $\mathrm{Bi}_{2} \mathrm{O}_{3}$ and organic vehicle (see Table 2).

Table 2

Composition of temperature/humidity sensitive pastes

\begin{tabular}{|c|c|c|}
\hline \multirow{2}{*}{ Constituents } & \multicolumn{2}{|c|}{ Content, \% mass } \\
\cline { 2 - 3 } & \multicolumn{2}{|c|}{$\mathrm{MuAl}_{2,1} \mathrm{Oi}_{4}$-based paste } \\
\hline Basic ceramics & 72.8 & 58 \\
\hline $\mathrm{Cu}_{0,1} \mathrm{Ni}_{0,8} \mathrm{Co}_{0,2} \mathrm{Mn}_{1,6} \mathrm{Mn}_{1,2} \mathrm{O}_{4} /$ & based paste \\
\hline Ecological glass & 2.9 & 4 \\
\hline Organic vehicle & 2.9 & 30 \\
\hline
\end{tabular}

The prepared paste were printed on alumina substrates (Rubalit $708 \mathrm{~S}$ ) with Ag-Pt electrodes using a using a manual screen-printing device equipped with a steel screen. Then, thick films were fired in furnace PEO-601-084. The typical planar type of design of the prepared films was shown elsewhere [14].

The topology of the obtained thick films was investigated using 3D-profilograph Rodenstock RM600. The electrical resistance of thermistor thick films was measured using temperature chambers MINI SABZERO, model MC-71 and HPS 222. The temperature constant $B_{25 / 85}$ for these thick films was calculated according to the Eq.[1]:

$$
B_{25 / 85}=2.3026 \cdot \log \left(\frac{R_{1}}{R_{2}}\right) \cdot \frac{T_{1} \cdot T_{2}}{T_{2}-T_{1}},
$$

where $R_{1}$ and $R_{2}$ were corresponding resistance at $T_{1}=25^{\circ} \mathrm{C}$ and $T_{2}=85^{\circ} \mathrm{C}$, accordingly.

The humidity-sensitivity of thick-film elements based on $\mathrm{MgAl}_{2} \mathrm{O}_{4}$ ceramics was evaluated on dependence of electrical resistance from relative humidity $(\mathrm{RH})$. The measurements were performed at $20^{\circ} \mathrm{C}$ and $1000 \mathrm{~Hz}$ frequency in direction of $\mathrm{RH}$ increase and in reverse one. 


\section{Result and discussion}

In respect to the obtained 3D-profilogramph data, the thickness of thick films based on temperature sensitive $\mathrm{Cu}_{0,1} \mathrm{Ni}_{0,1} \mathrm{Co}_{1,6} \mathrm{Mn}_{1,2} \mathrm{O}_{4}$ ceramics with $\mathrm{p}$-type of electrical conductivity, $\mathrm{Cu}_{0,1} \mathrm{Ni}_{0,8} \mathrm{Co}_{0,2} \mathrm{Mn}_{1,9} \mathrm{O}_{4}$ ceramics with n-type of electrical conductivity were 56.16 and $66.67 \mu \mathrm{m}$, accordingly. The thickness of thick films based on humidity sensitive dielectric $\mathrm{MgAl}_{2} \mathrm{O}_{4}$ ceramics was $52.08 \mu \mathrm{m}$.

All obtained separate temperature sensitive thick-film elements based on spinel-type $\mathrm{NiMn}_{2} \mathrm{O}_{4}-$ $\mathrm{CuMn} 2 \mathrm{O}_{4}-\mathrm{MnCo}_{2} \mathrm{O}_{4}$ ceramics have good electrophysical characteristics. These thick-film elements show exponential temperature dependences of resistances (Fig. 1). The values of $\mathrm{B}_{25 / 85}$ constant were $3653 \mathrm{~K}$ and $3673 \mathrm{~K}$ for $\mathrm{Cu}_{0,1} \mathrm{Ni}_{0,1} \mathrm{Co}_{1,6} \mathrm{Mn}_{1,2} \mathrm{O}_{4}$ and $\mathrm{Cu}_{0,1} \mathrm{Ni}_{0,8} \mathrm{Co}_{0,2} \mathrm{Mn}_{1,9} \mathrm{O}_{4}$ ceramics, respectively. The both thick films possess good temperature sensitivity in the region from 298 to $358 \mathrm{~K}$. The studied thick-film elements based on d-type $\mathrm{MgAl}_{2} \mathrm{O}_{4}$ ceramics possess linear dependence of electrical resistance from $\mathrm{RH}$ in semilogarithmic scale with minimal hysteresis in desorption cycle in the range of $\mathrm{RH} \sim 40-99 \%$ (see Fig. 2). Thus, these thick-film elements are suitable for humidity sensors working in the most important range of $\mathrm{RH}$.

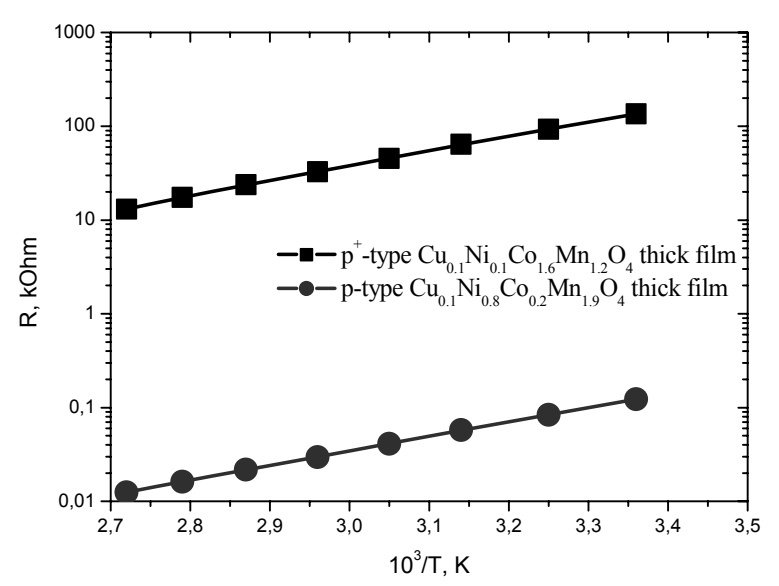

Fig. 1. Typical work characteristics for temperature sensitive thick films

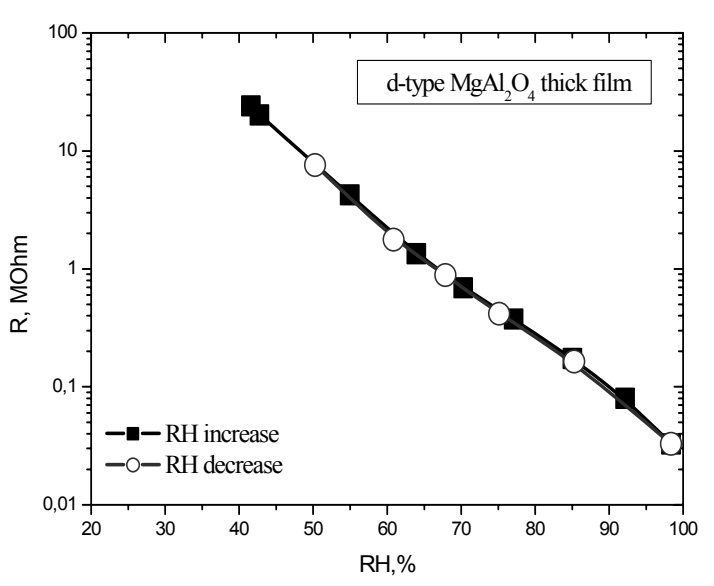

Fig. 2. Typical work characteristics for humidity sensitive thick films

Since all investigated separate components $\left(p-, p^{+}-\right.$and d-type thick films) are of the same chemical type (spinel-like) and possess high temperature/humidity sensitivities, they will be positively distinguished not only by wider functionality (simultaneous temperature-humidity sensing), but also unique functional reliability and stability. To prepare such multifunctional temperature/humidity sensitive elements, we can use typical design performance in respect to the scheme shown in Fig. 3. In the case under consideration, the main advantages proper to bulk transition-metal manganite ceramics (wide range of electrical resistance with high temperature sensitivity) and humidity-sensitive $\mathrm{MgAl}_{2} \mathrm{O}_{4}$ ceramics will be transformed into thick-film multilayers, resulting in a principally new and more stretched functionality.

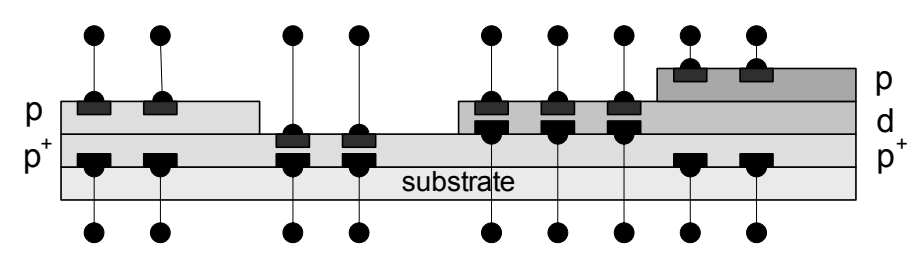

Fig. 3. Topological scheme illustrating integrated humidity/temperature sensing functionality in the developed spinel-type thick films

Within proposed configuration (see Fig. 3), a several simultaneous functions will be available via resistance measurements between different points of this multifunctional element: $p$-type thick-film element will be used as in-rush current limiter and temperature sensors utilizing current-voltage dependence of thick-film in $p+-p$ and $p-p+-p$ junctions will be used as temperature sensor utilizing thickfilm capacitor $p+-d-p$ with water-sensitive dielectric layer $d$. 


\section{Conclusions}

The separate temperature and humidity sensitive thick-film elements based on spinel-type $\mathrm{NiMn}_{2} \mathrm{O}_{4}$ CuMn ${ }_{2} \mathrm{O}_{4}-\mathrm{MnCo}_{2} \mathrm{O}_{4}$ manganites with $\mathrm{p}$ - and $\mathrm{p}^{+}$-types of electrical conductivity and dielectric magnesium aluminate $\mathrm{MgAl}_{2} \mathrm{O}_{4}$ were prepared using ecological glass constituents. These thick-film elements can be used as starting components to produce multifunctional integrated temperature/humidity sensors for effective environment monitoring and control.

\section{Acknowledgements}

The authors acknowledge research support from Science and Technology Center in Ukraine under STCU Project No 4277 and Internationales Büro des BMBF within BMBF-WTZ Project No UKR 06/006 (in the part of thick-film preparation).

\section{References}

1. Sheftel I.T., Thermoresistors, Nauka, Moscow, 1973, p. 415.

2. Zaharov V.I., Olesk A.O., Elektronnaja Tehnika, Ser. Radiodetali i Komponenty 63 (1989) 30.

3. Zaharov V.I., Olesk A.O., Film thermistors, Zarubeznaja Elektronnaja Tehnika 5 (1983) 43.

4. Zhong J., Bau H.H., Am. Ceram. Soc. Bull. 80 (2001) 39.

5. Feingold A.H., Wahlers R. L., Amstutz P., Huang C., Stein S.J., Mazzochette J., Microwave Journal $1(2000) 90$.

6. Qu W. et al., Meas. Sci. Technol. 11 (2000) 1111.

7. White N.W., Turner J.D., Meas. Sci. Technol. 8 (1997) 1.

8. Dziedzic A. et al., Meas. Sci. Technol. 8 (1997) 78.

9. Holc J., Sensors and Actuators B 26/27 (1995) 99.

10. Huang J., Mat. Sci. Eng. B 99 (2003) 523.

11. Brunets I., Shpotyuk O., Mrooz O., Altenburg H., Proc. of $24^{\text {th }}$ Intern. Conf. on Microelectronics. Nis, Serbia and Montenegro (2004) 503.

12. Vynnyk I., Hadzaman I., Klym H., Mrooz O., Shpotyuk O., Technology and Design in Electronics $2(2006) 60$

13. Shpotyuk O., Ingram A., Klym H., Vakiv M., Filipecki J., J. Europ. Ceram. Soc. 2520052981.

14. Klym H.I., Balitska V.O., Vakiv M.M., Brunets I.M., Shpotyuk O.I., Bull. Lviv Polytechnic National University: Solid-state electronics: theory, devices and application 510 (2004) 98. 